\title{
ANÁLISIS DE LAACCESIBILIDAD EN TRANSPORTE PÚBLICO AL PARQUE NACIONAL DE GARAJONAY (ISLA DE LA GOMERA): PROPUESTA PARA SU CORRECCIÓN ${ }^{1}$
}

\author{
José Ángel Hernández Luis \\ Departamento de Geografía. Universidad de Las Palmas de Gran Canaria \\ jose.hernandez@ulpgc.es
}

\section{RESUMEN}

El objetivo principal de este artículo es la realización de una diagnosis de la accesibilidad al Parque Nacional de Garajonay, para luego detectar los principales problemas, planteando posteriormente las alternativas más sostenibles de transporte hasta este paraje emblemático de la Isla. Partimos de la evaluación de diferentes encuestas, con el fin de evaluar la cantidad de desplazamientos (en el tiempo y en el espacio), proponiendo las soluciones pertinentes según los casos.

Palabras clave: accesibilidad, transporte público, Parque Nacional, visitantes, sostenibilidad.

\section{ABSTRACT}

The main objective of this paper focuses on a diagnosis of accessibility Garajonay National Park, and then identify the main problems, subsequently raising the sustainable transport alternatives to this iconic place on the Island. We start with the evaluation of different surveys, in order to assess the amount of displacement (in time and space), proposing solutions depending on the case.

Keywords: Accesibility, public transport, National Park, visitors, sustainability.

Fecha de recepción: marzo 2013.

Fecha de aceptación: diciembre 2013.

1 Este trabajo es fruto de un proyecto de investigación realizado por el autor de este artículo finalizado en 2013 y que llevó por título: «Estudio de alternativas para la conexión de los pueblos de la isla de La Gomera mediante un sistema de transporte, teniendo en cuenta los puntos de interés turísticos». Dicho proyecto fue financiado por el Excmo. Cabildo Insular de La Gomera y el programa «Volcanic Experience», con fondos del Gobierno de España y del Gobierno de Canarias. 


\section{INTRODUCCIÓN}

Este artículo se corresponde con una parte de un proyecto más amplio, realizado entre 2012 y 2013, con el objeto de analizar la viabilidad de la implantación de un transporte sostenible entre los diferentes enclaves de la isla de La Gomera, especialmente aquellos que presentaban un interés turístico. Como se deduce por tanto del título de este trabajo, solo hacemos referencia aquí al Parque Nacional de Garajonay, un espacio que representa solo el 10\% de la superficie insular, aunque con un atractivo turístico primario para los que deciden visitar la Isla.

Para realizar este cometido, realizamos en primera instancia una diagnosis del transporte en el Parque Nacional (demanda de visitantes, matriz de origen y destino, concentración diaria y horaria, etc.), identificando además los nodos principales susceptibles de visitas turísticas, en gran medida vinculados con la práctica del senderismo, aunque también miradores, etc.

Todo ello tiene como objetivo la identificación de los principales problemas de accesibilidad detectados (la falta de conectividad nodal del transporte público regular, la mala planificación de los horarios, la ausencia de una señalética adaptada al entorno, etc.), aportando las soluciones pertinentes en cada caso.

\section{BREVE VISIÓN DE LA BIBLIOGRAFÍA SOBRE TRANSPORTE SOSTENIBLE EN PARQUES NACIONALES}

Una estimable parte de la literatura científica sobre los parques nacionales se focaliza, evidentemente, hacia los problemas de estos espacios, como por ejemplo la foresta, la fauna, la erosión, etc., elementos éstos que cada vez son más afectados por la movilidad terrestre. Por ello mismo, cada vez cobran mayor interés los problemas de la movilidad en estos territorios, en tanto que son causantes de los principales impactos que allí se detectan (Burson, 2000; Turnbull, 2003; Dunning, 2005; Louter, 2006; White, 2007).

Si bien es cierto que existen algunos trabajos centrados en las experiencias que les suscita a los visitantes de dichos espacios la vivencia de permanecer en ellos en diferentes enclaves, como baluartes de paisajes emblemáticos (Turnbull, 2003; Louter, 2006); otras investigaciones presentan un carácter más aplicado, por ejemplo al evaluar el impacto de la accesibilidad y sus implicaciones, indagando por ejemplo en el problema del cambio climático, las emisiones contaminantes o acústicas (Burson, 2000; Anable, 2005; Guiver, 2007; Gössling, 2012); el diferente uso del transporte turístico desde el punto de vista de la percepción ambiental (Louter, 2006; Bamberg, 2007; Stradling, 2007); las derivaciones de los cambios modales hacia medios de transporte más sostenibles (Transport 2000 Trust, 2001; Dickinson, 2006; Dickinson y Robbins, 2007); o también la planificación de rutas turísticas para el transporte público (Lumsdon, 2006; Enoch, 2012).

Igualmente, la implementación de sistemas de transporte públicos para aplacar los problemas del transporte privado derivados de la congestión en espacios no urbanos, la mejora de la seguridad de los visitantes y la mejora de la percepción de estos espacios, ha sido un tema recurrente en multitud de trabajos (Turnbull, 2003; Dunning, 2005; Hedberg, 2011; Devkota, 2012), derivando en aportaciones que tienden a paliar estos impactos a través de tecnologías o transportes alternativos más sostenibles y con distinto éxito (Eaton, 1996; Daigle, 2004; White, 2007; Velaga, 2012); o también considerando el transporte público 
como disuasorio del privado y, por ende, como demandante de menos territorio debido a la construcción de nuevas carreteras (Retzlaff, 2000; Turnbull, 2003; Shiftan, 2006).

En suma, el presente trabajo realiza un acercamiento a los problemas del transporte motorizado en el Parque Nacional de Garajonay, realizando en primer lugar una diagnosis de la accesibilidad, para luego detectar las dificultades pertinentes y, en última instancia, proponer las correcciones oportunas, donde la mejora del transporte público a través de diversas iniciativas, es la solución principal, acercándonos a la metodología de los trabajos señalados en el párrafo anterior.

\section{UN PARQUE NACIONAL CON EL DISTINTIVO DE PATRIMONIO DE LA HUMANIDAD}

El Parque Nacional de Garajonay se creó según Ley 3/1981 de 25 de marzo. Este espacio, caracterizado sobre todo por la exuberante laurisilva que se desarrolla en él y que, recordemos es un relicto de la flora que existía en la ribera del Mediterráneo en el Terciario, tuvo por finalidad proteger la integridad de la gea, fauna, flora, vegetación, aguas y atmósfera, así como sus valores arqueológicos y, en definitiva, del conjunto de los ecosistemas del Parque Nacional.

En noviembre de 1986, la UNESCO incluyó Garajonay en su lista de espacios Patrimonio de la Humanidad. Otras protecciones que han avalado la relevancia de este espacio, se centran en que el Parque es por definición Área de Sensibilidad Ecológica en toda su superficie, a efectos de lo indicado en la Ley 11/1990, de 13 de julio, de Prevención de Impacto Ecológico. Además, diversos enclaves de la Isla, incluidos los del Parque Nacional, han sido declarados Lugares de Importancia Comunitaria (LIC). También el Parque Nacional tiene la consideración de Zona de Especial Protección para las Aves (ZEPA) según lo establecido en la Directiva 79/409/CEE relativa a la Conservación de las Aves Silvestres.

El Parque cuenta con una superficie de 3.984 Has. (algo más del $10 \%$ de la superficie de la superficie insular), y se extiende por las cotas más altas de la Isla. Aunque no hay asentamientos humanos dentro del Parque, existe una quincena de poblaciones situadas en las cabeceras de los barrancos que rodean el perímetro del Parque, y que están incluidas en la Zona Periférica de Protección (4.230 has.), más conocida como Pre-parque.

Por último, hay que señalar la importancia de las figuras: Parque Nacional y Patrimonio de la Humanidad, pues según una encuesta realizada en el segundo semestre de 2010, se llegó a la conclusión de que el 49 \% calificaba como «muy importante» para su visita el hecho de que dicho espacio fuese declarado como Parque Nacional, mientras que otro $17 \%$ lo consideraba como «importante» (Aider La Gomera, 2011: 23-24). Casi idénticas cifras se registraban cuando se les preguntaba por la consideración de Patrimonio de la Humanidad, lo que reafirma el gran atractivo que, para la visita de este espacio -y de la Isla por extensión-, tiene la declaración de ambas figuras.

\section{III.1. Evolución de la demanda de visitas al Parque Nacional}

Hay que constatar una cuestión metodológica de peso, pues la existencia de varios accesos al Parque Nacional de Garajonay, tanto por senderos como por carretera, dificultan enormemente la cuantificación de la visita y, por ende, el uso del Parque (Aider La Gomera, 2011: 182). 
Pues bien, según el Plan de Uso Público del Parque, la estimación del número de visitantes a dicho paraje se fundamenta en la evaluación de tres grandes grupos:

1. El turismo que pernocta en la Isla.

2. El visitante de un día, por tanto, según la Organización Mundial del Turismo (OMT), no se trataría específicamente de un turista, sino de un «excursionista».

3. La población inscrita en el Censo de población de la Isla.

A estos parámetros se le aplica un coeficiente de visita según la siguiente metodología que recogemos del mencionado documento:

1. Se obtiene el número total de personas que entran y salen de la Isla por puertos y aeropuerto y se divide por la mitad, pues se estima que la mitad son llegadas y la mitad salidas. A esta cifra se le resta un $20 \%$, que es la estimación que se hace del número de pasajeros locales.

2. Partimos de los turistas alojados en la Isla según las fuentes oficiales (INE e ISTAC).

3. Al total de turistas entrados se le resta el total de alojados y el dato obtenido se estima que son visitantes de un día. Se asume que todos los visitantes de un día acceden al Parque.

4. Según estimación del Parque Nacional, el 55.2 \% de los alojados visitan el Parque y lo hacen una media de 3.5 veces durante su estancia.

5. La población censada en la Isla se obtiene a partir de las fuentes oficiales (INE e ISTAC), estimándose que cada habitante local visita el Parque 2.5 veces al año. Este dato también se obtuvo mediante encuesta.

6. Se suma el total de visitas de cada tipología (visitantes de un día, visitantes alojados y población local) y se obtiene el total de visitantes del Parque.

Con esta metodología desde finales de los años ochenta -que puede ser mejorable por supuesto-, se puede decir que la afluencia de visitantes al Parque Nacional de Garajonay ha seguido una progresión netamente alcista, aunque con pequeños altibajos. De este modo, mientras en 1989 se contabilizaron unos 125 mil visitantes, 20 años más tarde la cifra alcanzó los 625 mil, esto es, un incremento del $400 \%$. No obstante, el aumento significativo a partir del año 2003 se debe a modificaciones puntuales en la metodología para contabilizar a los visitantes.

En cualquier caso, en el último año del que disponemos datos, es decir 2009, se registró una caída de 234 mil visitantes, esto es, un $27 \%$ menos en comparación con el año anterior, frente a una caída del $3 \%$ a nivel de toda la red de Parques Nacionales. No obstante, esta caída de las visitas, bien podría deberse al hecho de que cada vez con mayor frecuencia, muchos guías no dan la información de los visitantes que viajan consigo cuando por ejemplo llegan al Centro de Juego de Bolas, o simplemente se quedan en el patio, sin acceder al recinto.

Por espacios significativos dentro del Parque donde se registran los usuarios que por allí transitan, destacamos el mencionado Centro de Juego de Bolas. En éste, a partir del año 2000, se experimentó un aumento sustancial que superó el listón de las 130 mil visitas anuales, hasta llegar a los 195 mil en 2004. Desde entonces y hasta el presente, el número de visitantes ha disminuido considerablemente hasta registrarse menos de 100 mil en 2009, siendo fundamentalmente los visitantes guiados los que registran la mayor contracción, mientras los visitantes independientes rondan los 55 mil. Este último dato particularmente nos interesa en este trabajo, por cuanto los primeros visitan el Centro en transporte concertado, mientras que los segundos precisan de un transporte individual, pues hasta esta infraestructura no existe un transporte colectivo 


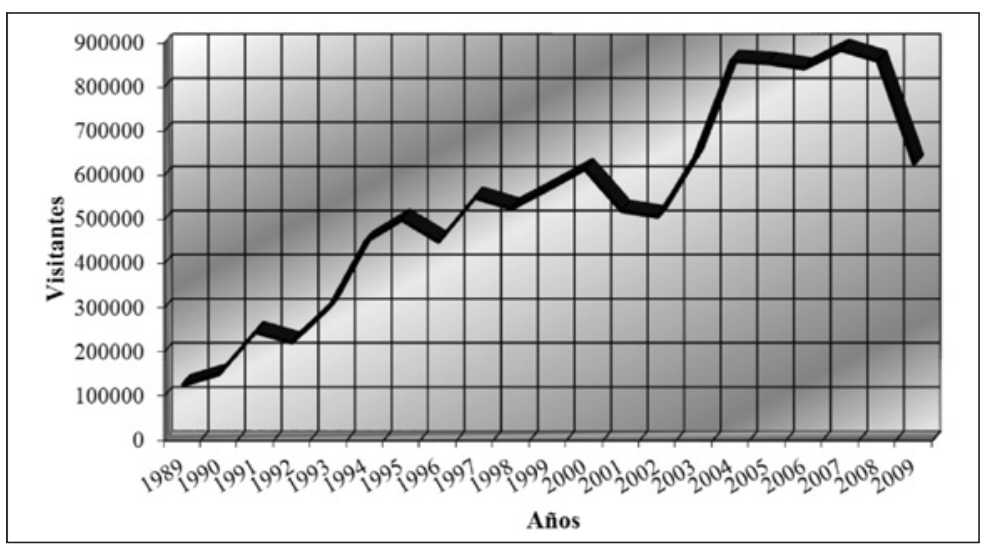

Fuente: Plan de Uso Público del Parque Nacional de Garajonay. Elaboración propia.

regular. Aún así, estos visitantes independientes también han sufrido un retroceso desde 2003 cuando alcanzaron la cifra de los 84 mil según la nueva metodología aplicada por el Parque.

Como decimos, son pues estos últimos los que sobre todo nos interesan para la elaboración de la demanda de transporte público, por cuanto reiteramos, los otros colectivos acceden a este Centro en transporte concertado. Así pues, elaboramos a continuación una tabla con la afluencia mensual de estos visitantes independientes, aunque referenciada a 2008, cuando se registraron unos 3 mil visitantes más en comparación con 2009:

Tabla 1

VISITAS SIN MEDIO DE TRANSPORTE CONCERTADO AL CENTRO DE JUEGO DE BOLAS

Y LA LAGUNA GRANDE SEGÚN MESES EN 2008

\begin{tabular}{|l|c|c|c|c|}
\cline { 2 - 5 } \multicolumn{1}{c|}{} & \multicolumn{2}{c|}{ Juego de Bolas } & \multicolumn{2}{c|}{ Laguna Grande* } \\
\hline Meses & Total & \% mensual & Total & \% mensual \\
\hline Enero & 4.600 & 7.92 & 6.200 & 7.77 \\
\hline Febrero & 6.000 & 10.33 & 4.400 & 5.51 \\
\hline Marzo & 6.200 & 10.67 & 7.000 & 8.77 \\
\hline Abril & 3.700 & 6.37 & 7.100 & 8.90 \\
\hline Mayo & 3.900 & 6.71 & 7.000 & 8.77 \\
\hline Junio & 2.900 & 4.99 & 5.500 & 6.89 \\
\hline Julio & 6.400 & 11.02 & 8.500 & 10.65 \\
\hline Agosto & 8.500 & 14.63 & 7.500 & 9.40 \\
\hline Septiembre & 4.000 & 6.88 & 6.500 & 8.15 \\
\hline Octubre & 3.800 & 6.54 & 8.300 & 10.40 \\
\hline Noviembre & 5.200 & 8.95 & 5.700 & 7.14 \\
\hline Diciembre & 2.900 & 4.99 & 6.100 & 7.64 \\
\hline Total & 58.100 & 100.00 & 79.800 & 100.00 \\
\hline
\end{tabular}

* La contabilización de La Laguna Grande se refiere al año 2009 y a todos los visitantes.

Fuente: Tragsatec, 2011. Elaboración propia. 
Así pues, la disparidad es más que notoria a lo largo del año, pues en el caso del Centro de Visitantes de Juego de Bolas, donde se han podido disgregar las visitas en grupo de las que llegan al recinto de forma independiente, tomando estos últimos como referencia, hemos constatado que en el mes de agosto se alcanza casi el $15 \%$ de las visitas del año. Ello significa una diferencia de 5.600 individuos por mes, o lo que es lo mismo, casi 200 personas más por día en agosto frente a otros meses de menor afluencia. Evidentemente, esto supone un dato bastante apreciable a la hora de evaluar la demanda de transporte desde dicho enclave hasta el Parque Nacional.

Por su parte, en La Laguna Grande, tomando todas las visitas (en grupo e individuales), la oscilación no es tan notoria como en el caso anterior, aunque también existen grandes disparidades, especialmente entre julio y octubre inclusive y el resto del año.

Desde el punto de vista de las visitas por días de la semana, también se detectan importantes disparidades, especialmente a favor de los miércoles frente a los domingos, siendo más del doble en el caso de La Laguna Grande y casi el doble en Juego de Bolas. En suma, exceptuando dicho día del fin de semana, el resto presenta una cierta homogeneidad desde el punto de vista de las visitas.

Por lo que respecta a la afluencia horaria, ésta se concentra particularmente entre las 12.00 y 14.00 horas en el Centro de Visitantes de Juego de Bolas, pues más del $50 \%$ de los visitantes que recibe este Centro se producen en esa franja horaria. En el caso de La Laguna Grande, también se repite lo mismo, aunque la franja horaria de máxima afluencia se extiende desde una hora más temprana, esto es, desde las 10.00 hasta las 14.00 horas, que es el período en el que se recibe algo más del $60 \%$ de las visitas del día. Como es evidente, aquí solo se está hablando de medias, si bien se han registrado puntas de más de 600 visitantes a las 13.00 horas en Juego de Bolas y de 330 visitantes entre las 12.00 y las 14.00 horas en La Laguna Grande (Tragsatec, 2011).

Tabla 2

TOTAL DE VISITAS AL CENTRO DE JUEGO DE BOLAS Y LA LAGUNA GRANDE SEGÚN HORAS EN 2009

\begin{tabular}{|c|c|c|c|c|}
\cline { 2 - 5 } \multicolumn{1}{c|}{} & \multicolumn{2}{c|}{ Juego de Bolas } & \multicolumn{2}{c|}{ Laguna Grande* } \\
\hline Franjas horarias & Total & \% horario & Total & \% horario \\
\hline $08.00-10.00$ & 40 & 6.15 & 120 & 16.22 \\
\hline $10.00-12.00$ & 180 & 27.69 & 230 & 31.08 \\
\hline $12.00-14.00$ & 350 & 53.85 & 240 & 32.43 \\
\hline $14.00-16.00$ & 80 & 12.31 & 150 & 20.27 \\
\hline Total & 650 & 100.00 & 740 & 100.00 \\
\hline
\end{tabular}

Fuente: Tragsatec, 2011. Elaboración propia.

En suma, la demanda de visitantes al Parque Nacional de Garajonay ha experimentado en los últimos años un continuado incremento, exceptuando 2009 en que cae de una manera importante (algo más de un 25 \%). Aún así, en este último año, la demanda superó los 600 mil, lo que supone una presión humana media diaria de más de 1.700 efectivos. No obstante, esta cifra es teórica, pues la disparidad temporal de la afluencia es la tónica general, con una tendencia a la concentración de las visitas en el período estival, sobre todo los días miércoles y 
en la franja horaria de mediodía. Esta localización puntual de la demanda, va a ser muy importante pues, para analizar la movilidad dentro del Parque Nacional y sus posibles alternativas.

\section{III.2. Matriz origen - destino de la demanda}

Los trayectos más frecuentemente realizados por los visitantes del Parque Nacional es un dato muy relevante para este trabajo, pues nos aproxima a la demanda existente de transporte, especialmente desde el exterior del Parque Nacional, aunque también dentro del mismo.

Figura 2

RED PRINCIPAL DE CARRETERAS Y NODOS PRINCIPALES DE LA ISLA DE LA GOMERA
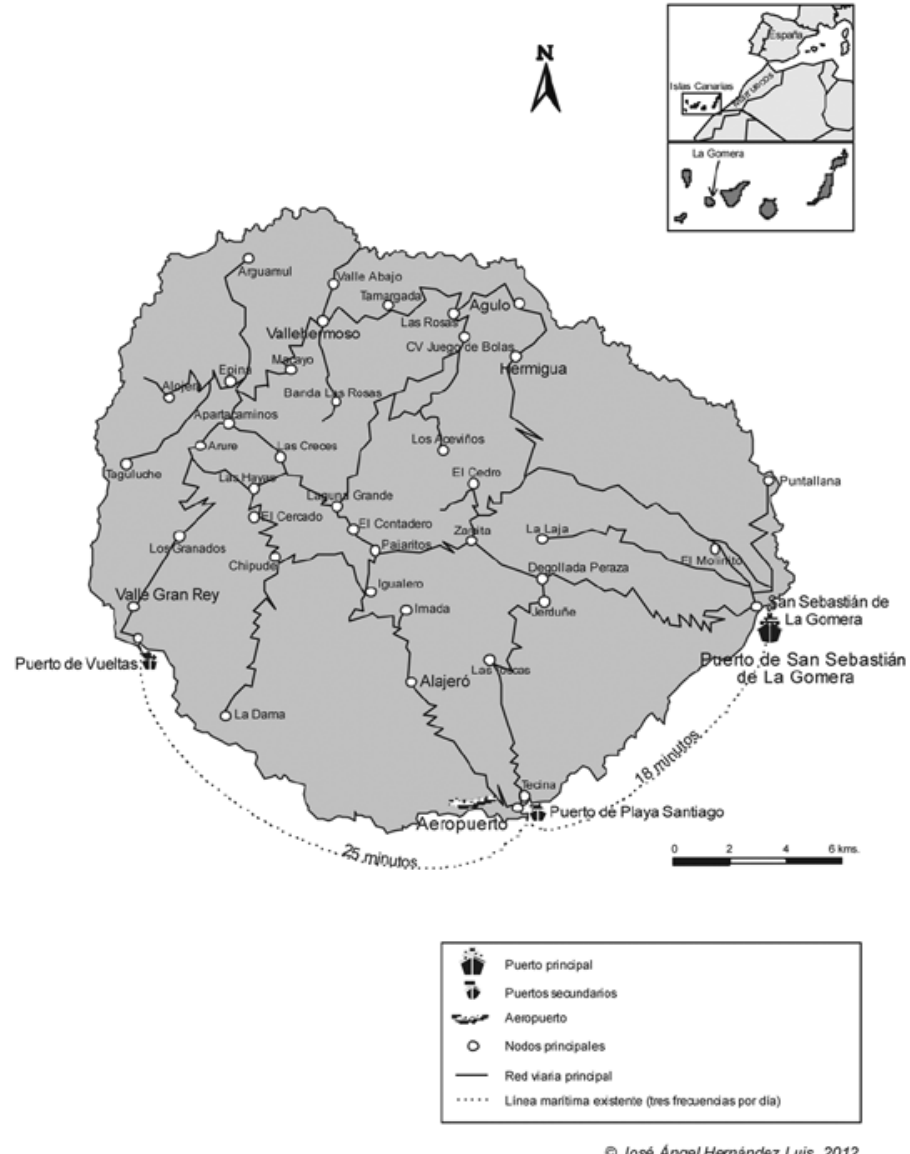

La información existente sobre este particular es bastante limitada, aunque la que tenemos disponible se puede considerar fiable y, lo que es también muy importante, bastante reciente, en concreto del segundo semestre del año 2010. Dicha información, a partir de una encuesta del Parque Nacional, ha detectado, en cifras aproximativas, que el $7 \%$ de los visitantes proce- 
den de apartamentos en el norte de la Isla, otro $8 \%$ de hoteles en la costa, un $5 \%$ de casas de turismo rural, y un $14 \%$ otros, donde se considerarían los hoteles o casas rurales de Hermigua, Agulo y Vallehermoso, además del camping de El Cedro. El restante porcentaje, esto es, un 66 $\%$, si está claro desde donde proceden, es decir, de los apartamentos de los tres municipios del sur, con la especificación además desde la localidad en si de origen, esto es, desde Valle Gran Rey, Playa Santiago y San Sebastián de La Gomera (Aider La Gomera, 2011: 44-45).

A partir de estos datos pues, hemos elaborado una estimación de los visitantes que llegan al Parque Nacional en transporte no discrecional, es decir, sin transporte público concertado, pues se supone que estos últimos no demandan un transporte público regular y casi todos proceden de viajes de un solo día desde Tenerife. En efecto, como nos señala el Plan de Uso Público del Parque Nacional, las excursiones organizadas en transporte público no regular y todoterreno tienen una presencia importante en el Parque. Suponen la principal actividad que realizan los excursionistas de un día. Como nos dice dicho documento, las rutas que siguen éstos «son prácticamente coincidentes, debido a varios factores, puntos de interés comunes, pocos lugares habilitados para el almuerzo de grandes grupos y limitación horaria por los ferrys. De esta situación deriva el principal problema de esta actividad, la masificación de los equipamientos donde tienen lugar las paradas, principalmente el Centro de Visitantes, La Laguna Grande, el sector de Los Roques y la pista que conecta el Centro de Visitantes con La Laguna Grande» (Tragsatec, 2011: 201-202).

Así pues, solo nos quedarían los turistas que pernoctan, además de los residentes, aunque ambos en cualquier momento también podrían demandar un transporte colectivo discrecional, además de coches de alquiler o incluso disponer de un vehículo privado, ante la apreciación por parte de éstos de que el transporte colectivo regular no ofrece unas garantías mínimas de movilidad. Así pues, hemos elaborado la siguiente tabla partiendo de la base de los datos de la Encuesta del Parque Nacional de Garajonay (2011) y que ilustra también la procedencia de los visitantes a dicha área protegida.

Como se observa en la tabla anterior, gran parte de los turistas que acceden al Parque Nacional pernoctan en Valle Gran Rey, totalizando algo más de un $50 \%$ y más de 80 mil efectivos al año. A bastante distancia le siguen los que pernoctan en Alajeró y San Sebastián de La Gomera (con alrededor de 20 mil turistas cada municipio), siendo aún menor la cifra de los que acceden desde el norte, no porque no tenga interés para ellos, sino porque evidentemente en los municipios del arco septentrional, existe una menor oferta de camas turísticas.

Si partimos de la base de que estos turistas, en su gran mayoría -y quizá con la sola excepción de una parte de los procedentes especialmente de Tenerife-, no cuentan con vehículo particular en la Isla, todos ellos necesitarían de un transporte público o bien alquilar un vehículo para acceder al Parque Nacional. A su vez, la población local que accede a dicho paraje y que el propio Parque estima que es de 2.5 veces al año, también tendría la opción -aunque ahora menos plausible ya que suele contar con vehículo particular en la Isla-, de trasladarse en transporte público. Sin embargo, los visitantes de un solo día que llegan a la Isla y que en 2010 representaron unos 476 mil, no precisan en principio de este transporte, pues en su inmensa mayoría llegan a La Gomera con el transporte terrestre ya concertado. Por tanto, los efectivos que exponemos en la siguiente tabla (turistas y población local), son lo que teóricamente podrían hacer uso de la demanda del transporte colectivo regular, en especial desde Valle Gran Rey y desde San Sebastián de La Gomera, pues desde estos dos 
municipios se registra el $64 \%$ de la demanda para acceder a la visita al Parque Nacional. De ahí que sea muy importante para esta área protegida la potenciación de la línea 1 de GuaguaGomera SAU entre ambas municipalidades, como así lo demuestra la alta demanda de turistas que en la frecuencia de las 08.00 de la mañana desde Valle Gran Rey se dirige todos los días hacia la capital insular y que luego discurre en sentido inverso entorno a las 15.30 horas desde la cumbre de la Isla hasta Valle Gran Rey. De igual manera, la línea 3 entre Alajeró y San Sebastián de La Gomera, al discurrir por Playa Santiago y Tecina (esta última localidad perteneciente al municipio capitalino), también tendría un gran potencial de clientela para la visita del Parque, aunque bastante más limitado, pues solo llega a la Degollada de Peraza, sirviendo de soporte a las rutas de senderismo que se inician desde este entorno.

Tabla 3

MUNICIPIOS DONDE PERNOCTABAN LOS TURISTAS QUE ACCEDÍAN AL PARQUE NACIONAL DE GARAJONAY EN 2010

\begin{tabular}{|c|c|c|}
\hline Alojamiento y entidades & \% estimado* & Volumen de turistas*** \\
\hline Apartamento (Valle Gran Rey) & 49 & \multirow{4}{*}{82.826} \\
\hline Hotel (Valle Gran Rey) & 2 & \\
\hline Casa rural (Valle Gran Rey) & 1 & \\
\hline Subtotal Valle Gran Rey & 52 & \\
\hline Apartamento (Playa Santiago, Alajeró) & 12 & \multirow{4}{*}{22.299} \\
\hline Hotel (Alajeró) & 1 & \\
\hline Casa rural (Alajeró) & 1 & \\
\hline Subtotal Alajeró & 14 & \\
\hline Apartamento (San Sebastián de La Gomera) & 4 & \multirow{4}{*}{19.114} \\
\hline Hotel (San Sebastián de La Gomera) & 7 & \\
\hline Casa rural (San Sebastián de La Gomera) & 1 & \\
\hline Subtotal San Sebastián de La Gomera & 12 & \\
\hline Apartamento (Hermigua) & 3 & \multirow{3}{*}{15.928} \\
\hline Hoteles y casas rurales (Hermigua) & 7 & \\
\hline Subtotal Hermigua & 10 & \\
\hline Apartamento (Agulo) & 1 & \multirow{3}{*}{7.964} \\
\hline Hoteles y casas rurales (Agulo) & 4 & \\
\hline Subtotal Agulo & 5 & \\
\hline Apartamento (Vallehermoso) & 3 & \multirow{3}{*}{11.150} \\
\hline Hoteles y casas rurales (Vallehermoso) & 4 & \\
\hline Subtotal Vallehermoso & 7 & \\
\hline TOTAL LA GOMERA & 100 & 159.281 \\
\hline
\end{tabular}

* El porcentaje estimado está basado en los datos reales aportados por Aider La Gomera, 2011; cfr. págs. 44-45.

** En 2010, el ISTAC nos facilita el dato que en La Gomera hubo una entrada de 95.955 turistas en hoteles y de 51.426 turistas en la planta extrahotelera, totalizando unos 147.381. A ello hay que añadirle los alojados en establecimientos rurales y que, con una ocupación media baja del $40 \%$ y una estancia media de 7.4 días (igual que los establecimientos extrahoteleros), nos darían unas 11.900 entradas. En total, las entradas regladas en establecimientos turísticos ascenderían a 159.281.

Fuente: Aider La Gomera, 2011 e ISTAC. Elaboración propia. 
Tabla 4

ESTIMACIÓN DE LOS TURISTAS Y DE LAPOBLACIÓN LOCAL QUE ACCEDÍAAL PARQUE NACIONAL DE GARAJONAY DESDE LOS DIFERENTES MUNICIPIOS DE LA ISLA EN 2010*

\begin{tabular}{|l|c|c|c|}
\hline Municipios & Turistas & Población local** & Total \\
\hline Valle Gran Rey & 82.826 & 12.875 & 95.701 \\
\hline San Sebastián de La Gomera & 19.114 & 22.730 & 41.844 \\
\hline Alajeró & 22.299 & 5.120 & 27.419 \\
\hline Hermigua & 15.928 & 5.458 & 21.386 \\
\hline Vallehermoso & 11.150 & 7.808 & 18.958 \\
\hline Agulo & 7.964 & 2.950 & 10.914 \\
\hline Total & 159.281 & 56.941 & 216.222 \\
\hline
\end{tabular}

* Se entiende que los restantes visitantes del Parque son excursionistas de un solo día (aproximadamente unos 476 mil en dicho año).

** Según la metodología que aplica el Plan de Uso Público del Parque Nacional de Garajonay (2011), se estima que cada habitante local visita el Parque Nacional unas 2.5 veces al año (Tragsatec, 2011; 182).

Fuente: Tragsatec, 2011 e ISTAC. Elaboración propia.

Así pues, tenemos una potencial demanda de transporte público regular que supera ostensiblemente los 200 mil visitantes del Parque Nacional que, sumados a los 476 mil procedentes de Tenerife -en su gran mayoría, como decíamos, demandantes de transporte público concertado-, suponen los casi 700 mil visitantes que estaría recibiendo el Parque Nacional en la actualidad.

\section{III.3. Enclaves susceptibles de visitas turísticas}

En este epígrafe haremos una recapitulación de los principales enclaves susceptibles de demanda de movilidad en el interior del Parque Nacional, en tanto que éstos nos van a identificar los puntos más importantes de visitas turísticas, aunque de por sí, toda la carretera central, así como las que confluyen en dicha vía, son un auténtico atractivo turístico. En efecto, recordamos que en el interior del Parque no existen actividades económicas -a excepción de las relacionadas exclusivamente con el propio Parque como por ejemplo el restaurante de La Laguna Grande-, ni tampoco espacios donde resida la población residente o turista, por lo que las visitas al Parque Nacional se podrían calificar estrictamente como de orden turístico o de excursión, a excepción del tránsito de la población a través de la carretera central, principalmente entre Valle Gran Rey y San Sebastián de La Gomera y que, como se sabe, esta vía para un trayecto terrestre entre ambos núcleos es de obligado tránsito.

Así pues, la red de senderos -y en bastante menor medida los miradores y áreas recreativas-, son los principales atractivos del Parque Nacional, sin olvidar otras actividades que también se pueden emprender, como por ejemplo el ciclismo de montaña, aunque solo allí donde esté permitido, básicamente en la red de carreteras del Parque, así como en las pistas en las que esté autorizado, pero no en la red de senderos donde no está permitida esta práctica.

Además de lo comentado, en el exterior del Parque Nacional se ubica el Centro de Visitantes, en concreto en Juego de Bolas, que sirve como soporte -aunque no indispensable para algunos turistas-, de la visita al Parque Nacional en si y que, evidentemente, se tendría que considerar a efectos de un nodo principal de demanda de transporte. 
Pues bien, vamos a centrarnos sobre todo en la red de senderos como gran justificante de la demanda de movilidad turística en el Parque Nacional. Para ello, hemos realizado una tabla que nos acerca al volumen de senderistas que, como media, se concentran en los principales puntos de partida o de llegada de los caminos, partiendo de la información que nos aporta el Plan de Uso Público del Parque Nacional, así como la encuesta del segundo semestre de 2010 del propio Parque Nacional que nos orientaba sobre el porcentaje de senderistas que utilizaban cada sendero.

Tabla 5

AFLUENCIA DE VISITANTES A LOS SENDEROS DEL PARQUE NACIONAL EN 2010*

\begin{tabular}{|l|c|c|c|}
\hline Senderos & $\%$ & $\begin{array}{c}\text { Senderistas } \\
\text { estimados }\end{array}$ & $\begin{array}{c}\text { Parada de bus más } \\
\text { cercana (en ms.) }\end{array}$ \\
\hline El Contadero - El Cedro - El Contadero & 19 & 63.650 & 1.300 (Pajaritos) \\
\hline Laguna Grande - Alto Garajonay - Laguna Grande & 16 & 53.600 & 3.700 (Pajaritos) \\
\hline El Contadero - Alto Garajonay - El Contadero & 13 & 43.550 & 1.300 (Pajaritos) \\
\hline La Laguna Grande II - La Laguna Grande II & 9 & 30.150 & 3.700 (Pajaritos) \\
\hline Pajaritos - Alto Garajonay - Pajaritos & 7 & 23.450 & 0 (Pajaritos) \\
\hline Ermita de Lourdes - Ermita de Lourdes & 4 & 13.400 & 4.300 (Pajaritos) \\
\hline La Laguna Grande I - La Laguna de Grande I & 4 & 13.400 & 3.700 (Pajaritos) \\
\hline Cañada de Jorge - Cañada de Jorge & 4 & 13.400 & 0 (El Raso) \\
\hline Las Creces - Las Creces & 3 & 10.050 & 0 (Las Creces) \\
\hline Reventón Oscuro - El Cedro - Reventón Oscuro & 3 & 10.050 & 1.400 (Zarcita) \\
\hline Pajaritos - Chorro del Cedro - Tajaqué - Pajaritos & 3 & 10.050 & 0 (Pajaritos) \\
\hline Raso Bruma - Risquillos Corgo - Raso Bruma & 2 & 6.700 & 0 (El Raso) \\
\hline Agando - Casa del Manco - Agando & 2 & 6.700 & 0 (Agando) \\
\hline El Bailadero - El Bailadero & 1 & 3.350 & 1.900 (Zarcita) \\
\hline Barranquillos - Barranquillos & 1 & 3.350 & 1.100 (Apartacaminos) \\
\hline Meseta Hermigua - Chorro Cedro - Meseta Hermigua & 1 & 3.350 & 4.500 (Zarcita) \\
\hline Pajaritos - Ajugal - Pajaritos & 1 & 3.350 & 0 (Pajaritos) \\
\hline Otros & 7 & 23.450 & ----- \\
\hline
\end{tabular}

* Los visitantes están referenciados a la estimación de senderistas según el Plan de Uso Público del Parque Nacional (Tragsatec, 2011; 225), partiendo de la base de la encuesta del segundo semestre de 2010 que establecía unos porcentajes de concentración de los senderistas en los puntos de partida o de llegada de los caminos (cfr. pág. 53). Fuente: Aider La Gomera, 2011, cfr. pág. 53 y Tragsatec, 2011, cfr. pág. 225. Elaboración propia.

Como se podrá comprobar, todos los senderos son de carácter circular, por lo que éste comienza en el mismo paraje que termina tras realizar un recorrido de escasos metros o incluso kilómetros, como por ejemplo el del Bailadero, cuya ida y vuelta supone menos de 1 kilómetro, mientras que el de El Contadero - Chorro de El Cedro casi alcanza los 6 kilómetros de ida, a lo que hay que añadirle un desnivel de más de 500 metros. De todos modos, y aunque aquí se hayan reflejado senderos de ida y vuelta, no es recomendable que éstos se hagan así, bien por su extensión o por su desnivel, especialmente para personas que no estén entrenadas en el hábito de caminar, pues la topografía de la Isla -y en particular la del Parque Nacional de Garajonay-, es extremadamente abrupta en algunos parajes. 
En cualquier caso, creemos que la lectura de la tabla anterior es contundente, ya que nos estaría indicando que existe una concentración muy marcada de los senderistas en dos grandes enclaves: por un lado El Contadero, con casi el $40 \%$ de los senderistas y, por otro, La Laguna Grande, con algo más del $30 \%$. En un término medio se situarían los parajes de Pajaritos y de Las Creces, con un 10 \% cada uno y el resto por debajo de ese listón. Ello supondría que, partiendo de la base de los 335 mil senderistas anuales a los que alude el Plan de Uso Público del Parque Nacional, algunos parajes como El Contadero rebasarían sobradamente los 100 mil senderistas al año, mientras que en La Laguna Grande se acercarían a esta cifra. En volumen de caminantes por día, mientras en El Contadero la cifra sería de 330, en La Laguna Grande se acercaría a los 270, siendo también relativamente importante la afluencia a Pajaritos y a Las Creces, con unos 80 - 100 senderistas por día como reflejamos en la siguiente tabla:

Tabla 6

CONCENTRACIÓN DE LA DEMANDA DE SENDERISTAS EN EL PARQUE NACIONAL DE GARAJONAY EN FUNCIÓN DE LAS PARADAS DE TRANSPORTE PÚBLICO REGULAR EN 2010

\begin{tabular}{|l|c|c|c|c|}
\hline Enclave aproximado & $\begin{array}{c}\text { Senderitas } \\
\text { estimados } \\
\text { en 2010 }\end{array}$ & $\begin{array}{c}\text { Senderistas } \\
\text { estimados } \\
\text { por día }\end{array}$ & $\begin{array}{c}\text { Parada de bus más } \\
\text { cercana (en ms.) }\end{array}$ & $\begin{array}{c}\text { Senderistas en } \\
\text { automóvil } \\
\text { por día* }\end{array}$ \\
\hline El Contadero & 120.600 & 330 & 1.300 (Pajaritos) & 131 \\
\hline La Laguna Grande & 97.150 & 266 & 3.700 (Pajaritos) & 106 \\
\hline Cruce de Pajaritos & 36.850 & 101 & 0 (Pajaritos) & 80 \\
\hline Las Creces & 30.150 & 83 & 0 (Las Creces) & 33 \\
\hline Reventón Oscuro & 16.750 & 46 & 1.400 (Zarcita) & 27 \\
\hline Roque de Agando & 6.700 & 18 & 0 (Agando) & 15 \\
\hline Barranquillos & 3.350 & 9 & 1.100 & 4 \\
\hline Otros & 23.450 & 64 & (Apartacaminos) & ----- \\
\hline
\end{tabular}

* Basado en el porcentaje de senderistas que accedían en automóvil en 2009 a La Laguna Grande, esto es, un 39.7 \% (que se extrapola a La Laguna Grande, El Contadero, Las Creces y Barranquillos); para El Cedro un $58.6 \%$ (que se estima para Reventón Oscuro); y para Tajaqué con un $79.5 \%$ (que se intuye corresponden con el Roque de Agando y el Cruce de Pajaritos).

Fuente: Aider La Gomera, 2011, cfr. pág. 53 y Tragsatec, 2011, cfr. págs. 191-192 y 225. Elaboración propia.

Pero sobre todo nos interesan los senderistas que acceden a estos enclaves en vehículos privados y de alquiler, además de los que llegan en transporte público regular, pues los que acceden en transporte público concertado no necesitan de un transporte más sostenible o ecológico, ya que se estarían desplazando en un transporte público. El objetivo pues, es identificar a los senderistas que sobre todo acceden a estos parajes en vehículos privados o de alquiler. Este extremo no es fácil, pero en una primera aproximación basándonos en las estadísticas que nos aporta el Plan de Uso Público del Parque Nacional (Tragsatec, 2011: 191192), podemos argumentar que los senderistas que como media llegaban a diario en 2010 a El Contadero en automóvil eran de 131, seguido de algo más de 100 en La Laguna Grande. A continuación, el Cruce de Pajaritos con 80 y el resto con cifras cercanas a 30 o menos. 
Como ya indicábamos más arriba, el $44 \%$ de los turistas y residentes que acceden al Parque Nacional proceden de Valle Gran Rey, mientras que un 19 \% de San Sebastián de La Gomera. Ello representa que algo más de un $60 \%$ de los accesos a dicho paraje podrían ser operados por la línea 1 de GuaguaGomera. Por su parte, el potencial de demanda desde Vallehermoso al Parque Nacional se reduce a un $9 \%$ del total que particularmente afectaría a la línea 4 entre Vallehermoso y La Dama. Con ello, estaríamos hablando del siguiente potencial:

Tabla 7

POTENCIAL DE DEMANDA TEÓRICA DIARIA DE SENDERISTAS AL PARQUE NACIONAL DE GARAJONAY EN LAS LIINEAS DE GUAGUAGOMERA QUE CRUZAN DICHO PARQUE NACIONAL*

\begin{tabular}{|l|c|c|}
\hline Enclave aproximado & Línea 1 & Línea 4 \\
\hline El Contadero & $83^{* *}$ & No accesible \\
\hline La Laguna Grande & $67 * *$ & No accesible \\
\hline Cruce de Pajaritos & 50 & No accesible \\
\hline Las Creces & 21 & 3 \\
\hline Reventón Oscuro & $17 * * *$ & No accesible \\
\hline Roque de Agando & 9 & No accesible \\
\hline Barranquillos & $3 * * *$ & 0 \\
\hline Total & 250 & 3 \\
\hline
\end{tabular}

* Línea 1 entre Valle Gran Rey y San Sebastián de La Gomera; Línea 4 entre Vallehermoso y La Dama.

** En estos enclaves no existe parada de esta línea pero podría crearse una nueva ruta (complementaria de la actual línea 1), que cruzase estos parajes con origen en Valle Gran Rey y destino en la capital insular.

*** La parada de la línea 1 más cercana a estos enclaves se encuentra a 1.400 metros en el Cruce de La Zarcita para Reventón Oscuro y a 1.100 metros en Apartacaminos para Barranquillos.

Fuente: Aider La Gomera, 2011, cfr. pág. 53 y Tragsatec, 2011, cfr. págs. 191-192 y 225. Elaboración propia.

Como se podrá comprobar, la línea 1 entre Valle Gran Rey y San Sebastián de La Gomera, tiene un potencial diario de 250 senderistas que podrían hacer uso del transporte colectivo regular, mientras que en la línea 4 , el potencial es muy débil, de solo 3 senderistas. El problema de la línea 1 es que solo un $43 \%$ de los principales enclaves susceptibles para la realización de senderismo, tienen una parada in situ o muy cercana, lo cual representa una demanda real de 80 senderistas diarios, que en viajes de ida y vuelta evidentemente serían del doble. Sin embargo, las paradas de El Contadero y de La Laguna Grande quedan sin cobertura, ya que la ruta transcurre por las poblaciones que se encuentran más al sur, por la carretera de Las Hayas a Igualero. No obstante, la demanda hacia La Laguna Grande y El Contadero representa el $60 \%$ de todos los senderistas potenciales de esta línea que se trasladan actualmente en automóvil y que podrían hacerlo en transporte público regular, representado 150 efectivos solo en viaje de ida.

Es por tanto un potencial que con unos óptimos horarios de a primera hora de la mañana (08.30 - 09.00 horas aproximadamente) y vuelta sobre las 13.00 - 14.00 horas desde el Parque Nacional, aunque siguiendo la ruta de Las Creces - La Laguna Grande - El Contadero - Pajaritos, serviría para captar esta alta demanda de visitantes al Parque. Además, es una buena solución para reforzar la línea entre Valle Gran Rey y San Sebastián de La Gomera que en la actualidad solo cuenta con cuatro servicios diarios en cada sentido. 


\section{ACCESIBILIDAD AL PARQUE NACIONAL}

\section{IV.1. Tipología de acceso según modos de transporte}

Según el Plan de Uso Público del Parque Nacional de Garajonay, el acceso a dicho paraje se realiza en su gran parte en medios de transporte mecanizados, por tanto dependientes de las energías fósiles, hecho que se repite en multitud de áreas protegidas (Eaton, 1996; White, 2007). Bien es verdad que, dependiendo del punto de toma de datos, los vehículos menos eficientes, como son los particulares y de alquiler, tienen una mayor o menor presencia, condicionado sobre todo por el punto de muestreo. Así por ejemplo, en el Centro de Visitantes de Juego de Bolas, el automóvil parece tener una representación muy alta, al margen de que la toma de datos se haya realizado en el mes de agosto, con lo que ello conlleva de sesgo. Pero también en Tajaqué o El Cedro, la representación del vehículo privado o de alquiler es más que importante. Solo en La Laguna Grande parece tener una mayor penetración el autobús, evidentemente concertados, pues los del transporte público regular no circulan por dicho paraje.

Además y lo que es más representativo, es que la presencia de automóviles en El Cedro y en La Laguna Grande ha ganado varios puntos porcentuales desde 2005 frente a otros modos de transporte, tendencia que francamente es insostenible, máxime cuando nos encontramos dentro de un Parque Nacional que es además Patrimonio de la Humanidad y que aspira también a ser Reserva de la Biosfera.

Tabla 8

TIPOLOGÍA DE ACCESO SEGÚN MODOS DE TRANSPORTE A DIVERSOS ENCLAVES DEL PARQUE NACIONAL DE GARAJONAY EN 2009 (EN PORCENTAJES)

\begin{tabular}{|l|c|c|c|c|c|}
\hline $\begin{array}{c}\text { Modos de } \\
\text { transporte }\end{array}$ & $\begin{array}{c}\text { C. V. de Juego } \\
\text { de Bolas }\end{array}$ & $\begin{array}{c}\text { Laguna } \\
\text { Grande }\end{array}$ & $\begin{array}{c}\text { Alto } \\
\text { Garajonay }\end{array}$ & El Cedro & Tajaqué \\
\hline Autobús & 23.00 & 49.00 & 0.00 & 4.10 & 9.40 \\
\hline Automóvil & 71.00 & 39.70 & 1.20 & 58.60 & 79.50 \\
\hline A pie & 3.00 & 0.20 & 97.40 & 37.10 & 9.90 \\
\hline Otros & 3.00 & 11.10 & 1.40 & 0.20 & 1.20 \\
\hline Total & 100.00 & 100.00 & 100.00 & 100.00 & 100.00 \\
\hline
\end{tabular}

Fuente: Tragsatec, 2011. Elaboración propia.

Igualmente, en una encuesta realizada por Aider La Gomera en el segundo semestre de 2010, el medio de transporte más utilizado por los visitantes del Parque Nacional para llegar a este paraje lo fue el automóvil en un $82 \%$ (74 \% lo era en vehículo de alquiler), seguido del transporte público regular a bastante distancia (un $15 \%$ ), lo que demuestra una vez más y en este caso de forma más acentuada, la casi omnipresencia del automóvil en el Parque como medio de locomoción principal, aunque con todos sus problemas medioambientales inherentes (Aider La Gomera, 2011: 28). A ello se le debería añadir otro $2 \%$ de los visitantes que accedían a dicho paraje en taxi. No obstante, en este apartado en concreto, a los turistas se les permitía responder más de un ítem, por lo que el resultado final supera el $100 \%$, de ahí que nos parezca incluso algo elevado el uso del transporte colectivo regular para acceder al Parque Nacional. 
Si a este incremento de la presión automovilística en el Parque le añadimos la concentración horaria de las visitas que ya puntualizábamos más arriba, tenemos todos los ingredientes para el incremento de la contaminación, tanto acústica como atmosférica. Además, este aumento es uno de los parámetros principales para que la sociedad demande una ampliación de las infraestructuras destinadas al automóvil, es decir, la del aumento de la superficie destinada a las carreteras y a los aparcamientos.

\section{IV.2. Accesibilidad nodal}

La disponibilidad física de conexión de un nodo con respecto al resto de la red, es una garantía «mínima» de accesibilidad, aunque no justifica de por si que ese nodo disponga de una buena accesibilidad con alguno o todos los restantes nodos de la red de transporte. Y es

\section{Figura 3 \\ NODOS PRINCIPALES Y LÍNEAS DEL TRANSPORTE PÚBLICO REGULAR \\ EN EL PARQUE NACIONAL DE GARAJONAY EN 2012}

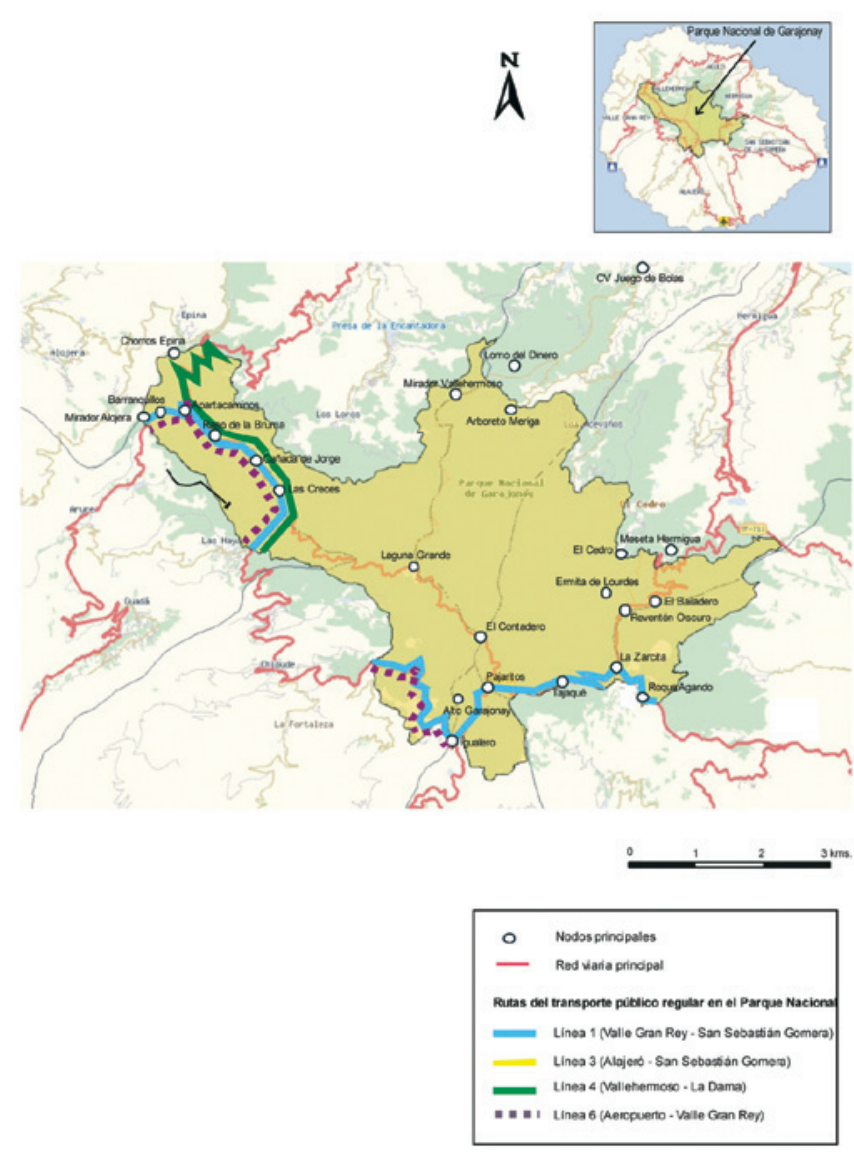

- Jose Angel Hemandez Luis, 2012 
que hay que partir de la base de que el análisis de la oferta horaria, conjuntamente con el sistema tarifario y al menos también los tiempos globales de transporte, confieren una calidad del servicio de transporte bien definida, por lo que el estudio de la accesibilidad nodal que desarrollamos en este punto no es ni mucho menos concluyente de la calidad del servicio de transporte público que se está prestando a los visitantes del Parque Nacional de Garajonay.

Para realizar un análisis de accesibilidad nodal del Parque Nacional, hemos efectuado una tabla con los principales puntos objeto de atracción de movilidad dentro de dicho paraje (comienzo y final de los senderos, áreas recreativas y miradores). Para ello hemos tomado como referencia para definir si un determinado enclave es accesible o no, la distancia de 500 metros como máximo hasta la parada del transporte público más cercana, aunque ello sea muy relativo, pues para un senderista, esta distancia puede ser perfectamente asumible, incluso hasta un kilómetro o más.

Pues bien, hemos tomado unos 14 nodos principales en el Parque Nacional, aunque uno, el del Centro de Visitantes del Parque Nacional, en Juego de Bolas, se encuentra bastante alejado de los límites del Parque Nacional. De esos 14 nodos, tan solo 5 presentan accesibilidad en transporte público regular, esto es, menos de un tercio de los considerados. Además, gran parte de la afluencia de visitantes se concentra en nodos que no son accesibles al transporte público regular, como son sobre todo La Laguna Grande y El Contadero.

Tabla 9

ACCESIBILIDAD EN TRANSPORTE PÚBLICO REGULAR A LOS PRINCIPALES NODOS DEL PARQUE NACIONAL DE GARAJONAY EN 2011

\begin{tabular}{|l|c|}
\hline Senderos (enclaves de inicio o de término) & $\begin{array}{c}\text { Accesibilidad a la parada de bus más cercana a } \\
\text { menos } \mathbf{~ d e ~ 5 0 0 ~} \text { ms. }\end{array}$ \\
\hline Pajaritos & $\mathrm{Si}$ \\
\hline Las Creces & $\mathrm{Si}$ \\
\hline Raso de la Bruma & $\mathrm{Si}$ \\
\hline Cañada de Jorge & $\mathrm{Si}$ \\
\hline Agando & $\mathrm{Si}$ \\
\hline El Contadero & No \\
\hline La Laguna Grande & No \\
\hline Ermita de Lourdes & No \\
\hline Reventón Oscuro & No \\
\hline El Cedro & No \\
\hline El Bailadero & No \\
\hline Meseta de Hermigua & No \\
\hline Barranquillos & No \\
\hline
\end{tabular}

Fuente: Trabajo de campo. Elaboración propia.

Es preciso pues, y en aras de alcanzar un transporte más sostenible en el Parque Nacional, la potenciación de un transporte público que podría ser concertado o regular, de tal modo que estos enclaves de mayor número de visitas estuviesen interconectados por medio de transporte público y éstos a su vez con el resto de la red insular de transporte público regular. 


\section{IV.3. Accesibilidad en franjas horarias}

El que exista una conectividad en transporte público entre uno o más nodos de la red de transportes, no garantiza en absoluto una óptima accesibilidad, sobre todo desde el punto de vista horario. Así pues, una baja frecuencia suele contar con unas cadencias de paso muy distantes unas de otras, con lo que no suele ser muy atractivo por ejemplo para la práctica del senderismo, que es una de las actividades principales que desempeñan los visitantes en el Parque Nacional de Garajonay. Así pues, el que el Parque Nacional cuente con conectividad del transporte público regular en determinados enclaves susceptibles de la práctica del senderismo (como por ejemplo Las Creces, cruces de Pajaritos y de la Zarcita, etc.), no presupone una buena accesibilidad, pues sobre todo depende, como decimos, de los horarios y también del sistema tarifario, además de otros factores no menos importantes como pueden ser los tiempos de transporte, la comodidad, etc.

A partir de estos principios teóricos, vamos a realizar una primera aproximación de la accesibilidad horaria entre las distintas entidades de población y los principales nodos del Parque Nacional, partiendo de la base de que solo se toman aquellos enclaves cuya parada de autobús más cercana se encuentra a menos de 500 metros.

Pues bien, hay que comentar que GuaguaGomera S.A.U. cuenta actualmente con unas 10 paradas en la línea 1 entre Valle Gran Rey y San Sebastián de La Gomera dentro de los límites del Parque Nacional (Apartacaminos, El Raso, Las Creces, Las Hayas, Las Tajoras, Igualero, Las Paredes, Pajaritos, La Zarcita y Roque de Agando). Igualmente, la línea 6 entre Valle Gran Rey y el aeropuerto sigue el mismo itinerario. Y, finalmente, la línea 4 entre Vallehermoso y La Dama, realiza también las cuatro primeras paradas, con la particularidad de que la anterior de Epina, puede servir de base para la visita al área recreativa de Los Chorros de Epina, esta última dentro del Parque Nacional, por lo que realmente estaríamos hablando de 11 paradas, aunque 4 de ellas no las vamos a considerar ya que no suponen un nodo de atracción para los visitantes por motivos de senderismo. Estas serían las paradas de Apartacaminos, Las Tajoras, Las Paredes y Las Hayas, si bien esta última sirve de soporte para la población que ya se encuentra fuera de los límites del Parque Nacional.

Tabla 10

ACCESIBILIDAD HORARIA EN DÍAS LABORALES EN TRANSPORTE PÚBLICO REGULARA LOS PRINCIPALES NODOS DEL PARQUE NACIONAL DE GARAJONAY EN 2011*

\begin{tabular}{|c|c|c|c|c|c|c|}
\hline $\begin{array}{l}\text { Paradas cercanas a } \\
\text { nodos importantes }\end{array}$ & Desde VGR & Desde SSG & $\begin{array}{c}\text { Desde } \\
\text { Vallehermoso }\end{array}$ & $\begin{array}{l}\text { Desde La } \\
\text { Dama }\end{array}$ & Desde VGR & $\begin{array}{c}\text { Desde } \\
\text { aeropuerto }\end{array}$ \\
\hline Pajaritos & $\begin{array}{l}06.10 ; 09.10 ; \\
15.10 ; 17.10\end{array}$ & $\begin{array}{l}11.10 ; 15.10 ; \\
19.10 ; 21.10\end{array}$ & ---- & --- & --- & ---- \\
\hline Las Creces & $\begin{array}{l}05.40 ; 08.40 ; \\
14.40 ; 16.40\end{array}$ & $\begin{array}{l}11.45 ; 15.45 ; \\
19.45 ; 21.45\end{array}$ & $06.55 ; 14.25$ & $08.40 ; 16.10$ & $08.50 ; 16.30$ & $10.20 ; 18.20$ \\
\hline Cañada de Jorge & $\begin{array}{l}05.35 ; 08.35 \\
14.35 ; 16.35\end{array}$ & $\begin{array}{l}11.50 ; 15.50 \\
19.50 ; 21.50\end{array}$ & $06.55 ; 14.25$ & $08.40 ; 16.10$ & $08.45 ; 16.25$ & $10.25 ; 18.25$ \\
\hline Raso de la Bruma & $\begin{array}{l}05.35 ; 08.35 \\
14.35 ; 16.35\end{array}$ & $\begin{array}{l}11.50 ; 15.50 \\
19.50 ; 21.50\end{array}$ & $06.50 ; 14.20$ & $08.45 ; 16.15$ & $08.45 ; 16.25$ & $10.25 ; 18.25$ \\
\hline
\end{tabular}

* Horarios aproximados de paso. Solo se consideran los nodos (enclaves del inicio o final de senderos) cuya parada del transporte público regular se encuentra a menos de 500 metros.

Fuente: GuaguaGomera, S.A.U. y trabajo de campo. Elaboración propia. 
La mayor cantidad de frecuencias y que por tanto presupone una mejor conectividad, pues habría que evaluar la adecuación de éstas a la demanda, se detecta en las paradas de Las Creces, Cañada de Jorge y Raso de La Bruma, con 8 frecuencias en cada sentido. No obstante, como los principales orígenes o destinos de los visitantes del Parque Nacional, como ya argumentábamos más arriba, se localizan en Valle Gran Rey y San Sebastián de La Gomera, presenta una utilidad nula el paso de las frecuencias desde Vallehermoso o desde La Dama, por lo que realmente estaríamos hablando de 4 ó 6 frecuencias únicamente si se consideran también las del aeropuerto - Playa Santiago, a menos que se tomen como origen y destino las mismas paradas aquí referenciadas.

Desde el punto de vista de la dispersión o separación horaria entre frecuencias, se aprecian fuertes disparidades, pues desde Valle Gran Rey entre la primera y la segunda frecuencia del día, existe una dispersión horaria de tres horas, mientras que entre la tercera y la cuarta es del doble, de seis horas, quedando un intervalo de dos horas entre la tercera y la última del día. Sin embargo, en el sentido inverso, existe una mayor equidad, con separaciones horarias de la operatividad de 3 - 4 horas y de 2 entre las últimas.

Particularmente, detectamos que existe una falta de accesibilidad importante debido al horario del transporte público en el sentido Valle Gran Rey - Parque Nacional, en concreto entre las 08.00 y las 14.00 horas, donde no se registra ninguna frecuencia, frente a las tres frecuencias entre las 14.00 y las 16.00 horas (dos que unen Valle Gran Rey con la capital insular una entre la primera y el aeropuerto). Así pues, parece oportuno reajustar los horarios como mínimo en estas líneas que señalamos de tal modo que -al margen de que se puedan incrementar las frecuencias en el futuro-, no existan estos grandes valles horarios que sin embargo se ven luego amortizados con una acumulación de las frecuencias en una franja horaria relativamente corta, especialmente en un municipio turístico como es el de Valle Gran Rey, donde los turistas se interesarían más por hacer uso del transporte colectivo si éste fuese más accesible, sobre todo desde el punto de vista horario. Esto lo demuestra que en 2010, un $76 \%$ de los encuestados hubiese preferido acceder al Parque Nacional en un medio de transporte más eficiente, y de ese $76 \%$, un 82 señaló que hubiera utilizado el transporte público (Aider La Gomera, 2011: 29). Partiendo de la base de que una buena parte de los turistas que pernoctan en la Isla y visitan el Parque Nacional, permanecen en Valle Gran Rey, es lógico atender esta demanda, pues además se detecta que una gran parte de la demanda de la frecuencia de las 08.00 horas entre Valle Gran Rey y San Sebastián de La Gomera son turistas que tienen como destino el Parque Nacional, hasta el punto de que la frecuencia con el aeropuerto de las 08.15 horas, ha servido algunas veces de refuerzo a esta primera frecuencia. No obstante, ello supone que los turistas, en una situación de ocio, se han de preparar (entre el aseo personal, desayuno, etc.) a las 07.00 horas e incluso antes, por lo que el grado de insatisfacción es alto partiendo de la base de que ya no existe otra frecuencia hasta las 14.00 horas.

En el sentido inverso, es decir, desde la capital insular a Valle Gran Rey, la primera frecuencia que alcanza el Parque Nacional lo hace ya a una hora relativamente tardía para los visitantes, pues sería después de las 11.00 horas, con lo que también sería muy interesante que se introdujese una nueva frecuencia en este sentido sobre las 08.00 horas, de tal modo que los visitantes comenzaran la visita de dicho paraje una hora más tarde. A su vez, los retornos a los puntos de origen (Valle Gran Rey o San Sebastián de La Gomera) y con los 
horarios actuales no se podrían realizar hasta las 15.00 horas aproximadamente, con lo que igualmente indicamos que debería existir una frecuencia en horario intermedio para hacer más atractiva la visita en este medio de transporte desde los dos principales núcleos demandantes de visitantes al Parque Nacional.

Por su parte, los horarios para la visita del Parque Nacional desde Vallehermoso y con regreso en horas de la tarde, son totalmente inaccesibles, de ahí que esta línea tenga una demanda muy baja. Igualmente, los horarios con el aeropuerto desde Valle Gran Rey, aunque están a expensas de los horarios aéreos, solo permiten una razonable utilización en el sentido hacia Valle Gran Rey en la primera frecuencia, mientras que el viaje de vuelta al aeropuerto y Playa Santiago vuelve a ser relativamente tardío.

\section{IV.4. Accesibilidad económica}

Realizamos aquí una somera evaluación del coste que les supone a los usuarios (turistas o residentes), el acceso al Parque Nacional en transporte público regular y su cotejo con otros medios de transporte alternativos aunque menos eficientes desde el punto de vista energético, como pueden ser los automóviles privados, los vehículos de alquiler e incluso los taxis.

Pues bien, vamos a exponer en la siguiente tabla una relación de las tarifas aplicadas en los trayectos más demandados con el Parque Nacional, significando una media de 0.13 euros por kilómetro. En general, se ha establecido el modelo de favorecer los trayectos que cuentan con conexión directa, penalizando los que tienen que realizar transbordo en San Sebastián de La Gomera, además de la línea de Vallehermoso a La Dama, previo tránsito por el Parque Nacional.

Tabla 11

TARIFAS EN TRANSPORTE PÚBLICO REGULAR DE LOS TRAYECTOS MÁS DEMANDADOS ENTRE LAS DISTINTAS ENTIDADES Y EL PARQUE NACIONAL EN MARZO DE 2012

\begin{tabular}{|l|l|c|c|}
\hline Origen & Destino & Tarifa de ida (en €) & Tarifa / km. \\
\hline S.S. de La Gomera & Cruce Pajaritos & 2.00 & 0.10 \\
\hline S.S. de La Gomera & Las Creces & 3.00 & 0.08 \\
\hline Valle Gran Rey & Cruce Pajaritos & 4.00 & 0.12 \\
\hline Valle Gran Rey & Las Creces & 2.00 & 0.11 \\
\hline Playa Santiago & Cruce Pajaritos & $4.00^{*}$ & 0.19 \\
\hline Playa Santiago & Las Creces & $5.00^{*}$ & 0.15 \\
\hline Hermigua & Cruce Pajaritos & $4.50^{*}$ & 0.12 \\
\hline Hermigua & Las Creces & $5.50^{*}$ & 0.10 \\
\hline Agulo & Cruce Pajaritos & $5.00^{*}$ & 0.11 \\
\hline Agulo & Las Creces & $6.00^{*}$ & 0.10 \\
\hline Vallehermoso & Cruce Pajaritos & $4.50^{*}$ & 0.16 \\
\hline Vallehermoso & Las Creces & 2.50 & 0.21 \\
\hline
\end{tabular}

* Trayectos con transbordo en San Sebastián de La Gomera, en la Degollada de Peraza o en el aeropuerto. Fuente: GuaguaGomera S.A.U. Elaboración propia. 
Por otra parte, la accesibilidad económica en diferentes medios de transporte hasta el Parque Nacional, queda mejor demostrada realizando una comparación entre distintos medios de transporte (el público regular, el vehículo de alquiler y el taxi) desde las principales entidades demográficas y turísticas hasta el Parque Nacional. Hay que partir de la base de que la tarifa vigente por kilómetro en el taxi es de 0.54 euros en los días laborales, siendo un $12 \%$ más elevada en las jornadas festivas. Como se sabe, la particularidad del taxi es que éste ingresa del cliente tanto el kilometraje de ida como el de vuelta, mientras que por ejemplo en el transporte colectivo público solo se estaría sufragando el coste de ida. De este modo tenemos que mientras en el transporte público regular la tarifa media asciende a unos 0.13 euros por kilómetro, en el taxi realmente supondría 1.07 euros, es decir, 8.2 veces más.

Tabla 12

TARIFAS DE IDA EN TAXI, TRANSPORTE PÚBLICO REGULAR Y COCHES DE ALQUILER EN LOS TRAYECTOS MÁS REPRESENTATIVOS HASTA EL PARQUE NACIONAL DE GARAJONAY EN MARZO DE 2011 (EN EUROS)

\begin{tabular}{|c|c|c|c|c|c|c|}
\hline \multirow[b]{2}{*}{ Origen } & \multirow[b]{2}{*}{ Destino } & \multirow[b]{2}{*}{ Taxi } & \multirow[b]{2}{*}{ Bus } & \multirow[b]{2}{*}{$\begin{array}{l}\text { Vehículo } \\
\text { alquiler* }\end{array}$} & \multicolumn{2}{|c|}{ Diferencia \% } \\
\hline & & & & & $\begin{array}{c}\text { Taxi - } \\
\text { bus }\end{array}$ & $\begin{array}{c}\text { Taxi - Veh. } \\
\text { alquiler }\end{array}$ \\
\hline S.S.de La Gomera & Cruce Pajaritos & 23 & 2 & 31 & 1050 & -26 \\
\hline S.S. de La Gomera & Las Creces & 41 & 3 & 32 & 1267 & 28 \\
\hline Valle Gran Rey & Cruce Pajaritos & 27 & 4 & 32 & 575 & -16 \\
\hline Valle Gran Rey & Las Creces & 20 & 2 & 31 & 900 & -35 \\
\hline Playa Santiago & Cruce Pajaritos & 23 & $4 * *$ & 32 & 475 & -28 \\
\hline Playa Santiago & Las Creces & 32 & $5 * *$ & 32 & 540 & 0 \\
\hline Hermigua & Cruce Pajaritos & 12 & $4.50 * *$ & 31 & 167 & -61 \\
\hline Hermigua & Las Creces & 21 & $5.50 * *$ & 32 & 282 & -33 \\
\hline Agulo & Cruce Pajaritos & 19 & $5 * *$ & 31 & 280 & -39 \\
\hline Agulo & Las Creces & 25 & $6 * *$ & 32 & 317 & -22 \\
\hline Vallehermoso & Cruce Pajaritos & 25 & $4.50 * *$ & 32 & 456 & -22 \\
\hline Vallehermoso & Las Creces & 14 & 2.50 & 31 & 460 & -55 \\
\hline
\end{tabular}

* Se ha tomado como coste del vehículo de alquiler en un solo día, un automóvil básico incluyendo seguros (30 euros), con un consumo de combustible estimado de 8 litros cada 100 kilómetros y a un coste medio de 1 euro por litro. Al igual que los tramos realizados en taxi y guagua, solo se considera el coste del combustible del viaje de ida. ** Trayectos con transbordo en San Sebastián de La Gomera, en la Degollada de Peraza o en el aeropuerto.

Fuente: GuaguaGomera S.A.U., Excmo. Cabildo Insular de La Gomera y trabajo de campo. Elaboración propia.

Pues bien, en una primera aproximación a las tarifas comparativas de los diferentes medios de transporte, el taxi llega a ser incluso más de un $1.000 \%$ más oneroso en comparación con el autobús, especialmente entre los trayectos más distantes como entre la capital insular y los enclaves de referencia en el Parque Nacional (Las Creces y el cruce de Pajaritos), mientras que la ausencia de una conexión central norte - sur del transporte público regular, obliga a los viajeros de este medio de transporte a efectuar un rodeo de tal modo que, por ejemplo desde Hermigua, se trasladarían a San Sebastián de La Gomera y desde ahí al Parque Nacional. Sin embargo, la carretera central desde aproximadamente el mirador de La Carbonera hasta el cruce de La Zarcita -y que es una vía ampliamente empleada para los desplazamientos norte 
- sur y viceversa-, consigue que el taxi y el vehículo de alquiler tomen una gran ventaja frente al transporte público, aunque tampoco se llegan a igualar las tarifas. De todos modos, las tarifas del transporte público aquí expuestas representan el coste de transportar a un solo viajero, mientras que como se sabe, un mayor índice de ocupación de los taxis o de los vehículos de alquiler, estaría acercando su coste al del transporte público regular.

Hay que destacar que el coste del vehículo de alquiler habría que considerarlo como ficticio, pues éste se emplea en la mayor parte de los casos para realizar varios tramos al día, incluso la circunvalación de la Isla. Por ello, el coste real de todos los tramos que se realizan a diario en este medio de transporte puede llegar a ser más económico en relación con el transporte público regular, máxime si como mínimo, el vehículo de alquiler transporta a tres o más personas.

Pero sin duda y en aras de que el transporte público regular sea aún más competitivo desde el punto de vista tarifario, especialmente para los trayectos que requieran un determinado rodeo frente a otros medios de transporte, sugerimos la implantación de un sistema de bonos -o de tarifa plana-, en el que al menos solo existiesen dos tarifas, esto es, los trayectos inferiores a un determinado kilometraje ( $10 \mathrm{kms}$. por ejemplo), oscilando las tarifas entre $1 \mathrm{y}$ 2 euros, y por encima de esta distancia con tarifas entre 2 y 4 euros como máximo.

\section{IDENTIFICACIÓN DE LA FALTA DE ACCESIBILIDAD}

\section{V.1. Tipificación de los principales problemas de accesibilidad}

Como se deduce de varios informes, entre ellos el más reciente de AIDER La Gomera (2011), el perfil del visitante que accede al Parque Nacional demanda un medio de transporte cada vez más sostenible y que sirva de soporte a su principal actividad en dicho paraje, esto es, la del senderismo. Este perfil se identifica con un alto nivel cultural y una elevada preocupación medioambiental, sobre todo por la procedencia de éstos (en gran parte alemanes y austriacos), y muy interesado en realizar senderismo al menos tres días durante su estancia en La Gomera. Es un perfil que demanda un buen servicio de transporte público, por cuanto el senderismo es precisamente una actividad que, en una buena parte de las rutas, comienzan y finalizan en distintos enclaves, siendo por tanto muy difícil la utilización de un vehículo de alquiler para este fin.

Pues bien, vamos a identificar los principales inconvenientes para el acceso a dicho paraje:

1. Conectividad nodal: En el Parque Nacional existen varios enclaves que no cuentan con cobertura del transporte público regular y que, además, son muy importantes en cuanto a generación de viajes, como es el caso de El Contadero y La Laguna Grande, aunque también El Cedro, el Centro de Visitantes de Juego de Bolas (en el exterior del Parque), Los Barranquillos, etc. Por tanto, sería idóneo que al menos en las dos primeras existiese una conexión de autobuses regulares, mientras que en las restantes constasen al menos conexiones de transporte a la demanda, para lo cual se diseñaron las rutas correspondientes.

2. Horarios: Las líneas de GuaguaGomera, S.A.U., que cruzan el Parque Nacional son la 1 (Valle Gran Rey - San Sebastián de La Gomera), la 4 (Vallehermoso - La Dama) y la 6 (Valle Gran Rey - aeropuerto). Las dos últimas presentan solo dos frecuencias 
diarias en cada uno de los sentidos. Particularmente en la línea 1, es necesario disminuir la dispersión horaria existente, sobre todo en el sentido Valle Gran Rey - San Sebastián de La Gomera en horas de las mañana, pues entre las 08.00 y las 14.00 horas no existe ninguna frecuencia.

3. Accesibilidad económica: Desde el punto de vista de la accesibilidad económica, parece muy pertinente la implantación de bonos que reporten un mayor uso de este transporte, así como tarifas planas en función de las distancias.

4. Vehículos para el transporte: En general se detecta un sobredimensionamiento de la oferta, con vehículos de 55 plazas en horas de escasa demanda, como por ejemplo las frecuencias de las 05.00 horas entre Valle Gran Rey y San Sebastián de La Gomera, y la de las 20.30 horas en sentido inverso, donde solo se registran 4 pasajeros en cada una de ellas como media. Sin embargo, en la frecuencia de las 08.00 horas entre Valle Gran Rey y la capital insular, la demanda es alta, viéndose necesario a veces -aunque en escasas ocasiones-, la necesidad de ampliar el servicio.

5. Infraestructura para el transporte: De las diez paradas existentes del autobús regular en el Parque Nacional, solo dos cuentan con marquesinas, mientras que las restantes no disponen siquiera de una señal identificativa de estas paradas. Parece pues necesario que sobre todo los enclaves de Las Creces, Pajaritos y La Zarcita, deberían contar al menos con marquesinas y el resto en una primera fase con la señalética pertinente con los correspondientes horarios y líneas.

6. Transporte de personas con movilidad reducida: En la actualidad, no existen autobuses del servicio regular adaptados para el transporte de estas personas, por lo que es una situación que debería regularizarse en el futuro, sobre todo por el creciente interés del turismo en joëlette.

7. Transporte de bicicletas: En los autobuses de 18 plazas es donde nos encontramos el mayor problema, especialmente en el de la primera hora de la mañana desde Valle Gran Rey al aeropuerto por el Parque Nacional. Decimos ello porque en una situación normal, esta frecuencia transporta como media unos 8 pasajeros, aunque todos ellos no tengan como destino el aeropuerto insular. Por tanto, si al menos la mitad de ellos desplaza equipaje, el transporte de bicicletas tiende a complicarse, evidentemente por falta de espacio.

\section{CONCLUSIONES}

El Parque Nacional de Garajonay sufre una presión humana de más de 600 mil visitantes al año, es decir, unos 1.700 diarios con una concentración espacial y horaria particularmente importante en el estío y en las horas centrales del día. Este hecho va a condicionar en demasía la movilidad, en gran medida turística procedente de los municipios de Valle Gran Rey y de San Sebastián de La Gomera (un 64\% de las visitas a este espacio desde toda la Isla).

Una de las actividades más importantes que se desarrollan en Garajonay es el turismo de senderos, actividad ésta altamente demandante de un transporte público regular. Estimamos que tan solo El Contadero, estaría siendo frecuentado por una media de 330 senderistas por jornada, de los que 130 lo harían en automóvil. En La Laguna Grande, el otro gran punto de concentración de los senderistas, las cifras serían de casi 270 diarios y algo más de 100 al día en automóvil. 
Como consecuencia sobre todo de las deficiencias nodales y horarias que experimenta el transporte público regular de la Isla en su conexión con el Parque Nacional, y que se plasma especialmente en la línea 1 entre los municipios de Valle Gran Rey y de San Sebastián de La Gomera, el crecimiento de la afluencia en medios de transporte privados -sobre todo en coches de alquiler-, ha experimentado un auge muy importante en los últimos años, con una estimable afección en cuanto a necesidad de nuevo espacio para el aparcamiento, la contaminación atmosférica y acústica, etc.

Por todo ello, hemos procedido a realizar una metodología de análisis de la accesibilidad, identificando unos 14 nodos principales en el Parque Nacional, demandantes de transporte público regular, aunque tan solo 5 de ellos presentan accesibilidad en el citado transporte, esto es, menos de un tercio de los considerados. Además, gran parte de la afluencia de visitantes se concentra en nodos que no son accesibles al transporte público regular, como son sobre todo La Laguna Grande y El Contadero. Si a ello le añadimos la mentada falta de accesibilidad horaria para los 5 nodos conectados con el resto de la red insular, una política de tarifas no incentivadora, la escasa adaptación de los vehículos para el transporte de las bicicletas, etc., evidencia que es necesario un cambio significativo de rumbo en el modo de operar el transporte público regular en dicho paraje emblemático.

Para la consecución de lo anteriormente comentado, hemos propuesto una línea de transporte complementaria en el Parque Nacional que cubra precisamente los nodos de mayor demanda de movilidad (La Laguna Grande y El Contadero), un concienzudo cuadro horario por líneas ajustados a la demanda, vehículos igualmente adaptados a la demanda que se experimenta según los horarios, etc., sin olvidar una política de señalética y de marquesinas adaptadas al entorno del Parque Nacional. Así pues, la metodología aplicada a este trabajo, puede ser extrapolable a otros espacios emblemáticos, ya sean paisajes naturales protegidos o humanos, en aras de implementar un transporte público más sostenible dentro de las tendencias que marca la Unión Europea.

\section{BIBLIOGRAFÍA}

AIDER LA GOMERA (2011): Estudio de opinión sobre la calidad de la visita en el Parque Nacional de Garajonay. Informe encuestas. Parque Nacional de Garajonay (inédito).

ANABLE, J. (2005): «CComplacent car addicts' or 'Aspiring environmentalists'?. Identifying travel behaviour segments using attitude theory». Transport Policy, 12.

BAMBERG, S. et Al. (2007): «Social context, personal norms and the use of public transportation: Two field studies». Journal of Environmental Psychology, 27.

BURSON, S. L. (2000): «The effect of vehicle traffic on wildlife in Denali National Park». Artic, 53.

COMISIÓN EUROPEA (2006): Por una Europa en movimiento. Movilidad sostenible para nuestro continente. Ed. Comisión de las Comunidades Europeas, Luxemburgo.

CABILDO INSULAR DE LA GOMERA (2010): Plan Insular de Ordenación de La Gomera. Cabildo Insular de La Gomera y Consejería de Política Territorial del Gobierno de Canarias (aprobación inicial).

DAIGLE, J. y ZINMERMAN, C. (2004): «The convergence of transportation, information technology and visitor experience at Acadia National Park». Journal of Travel Research, 43. 
DEVKOTA, B. et Al. (2012): «Planning for non-motorized travel in rural Nepal: a role for geographic information systems». Journal of Transport Geography, vol. 24.

DICKINSON, J. (2006): «Local transport and social representations: challenging the assumptions for sustainable tourism». Journal of Sustainable Tourism, 14.

DICKINSON, J. y ROBBINS, D. (2007): «Using the car in a fragile rural tourist destination: a social representations perspective». Journal of Transport Geography, 15-2.

DUNNING, A. (2005): «Impacts of transit in national parks and gateway communities». Transportation Research Record, Journal of the Transportation Research Board, 1931.

EATON, B. y HOLDING, D. (1996): «The evaluation of public transport alternatives to the car in British National Parks». Journal of Transport Geography, 4-1.

ENOCH, M. (2012): Sustainable Transport, Mobility Management and Travel Plans. Ed. Ashgate Pub Co.

GÖSSLING, S. et al. (2012): «Consumer behaviour and demand response of tourists to climate change». Annals of Tourism Research, 39-1.

GUIVER, J. et al. (2007): «Do buses help meet tourism objectives?. The contribution and potential of scheduled buses in rural destination areas». Transport Policy, 14.

HALLO, J. y MANNING, R. (2009): «Transportation and recreation: a case study of visitors driving for pleasure at Acadia National Park». Journal of Transport Geography, 17-6.

HEDBERG, Ch. y DO CARMO, R. M. (2011): Translocal Ruralism: Mobility and Connectivity in European Rural Spaces. Ed. Springer.

HERNÁNDEZ LUIS, J. Á. (2007): «Efectos territoriales del actual modelo de transporte terrestre en Canarias». Ciudad y Territorio. Estudios Territoriales, 154.

KAMRUZZAMAN, Md. y HINE, J. (2011): «Participation index: a measure to identify rural transport disadvantage? ». Journal of Transport Geography, 19-4.

LOUTER, D. (2006): Windshield Wilderness: Cars, Roads, and Nature in Washington's National Parks. Seattle. University of Washington Press.

LUMSDON, L. (2006): «Factors affecting the design of tourism bus services». Annals of Tourism Research, 33-3.

MINISTERIO DE FOMENTO (2005): Plan Estratégico de Infraestructuras y Transporte (PEIT). Madrid.

MINISTERIO DE MEDIO AMBIENTE (2005 a): Proyecto de revisión del Plan Rector de Uso y Gestión del Parque Nacional de Garajonay. Diagnóstico de gestión del Parque Nacional de Garajonay para la revisión del PRUG (inédito).

MINISTERIO DE MEDIO AMBIENTE (2005 b): Parque Nacional de Garajonay. Memoria Anual 2005 (inédito).

MINISTERIO DE OBRAS PÚBLICAS Y TRANSPORTES (1992): Guías metodológicas para la elaboración de estudios de impacto ambiental: 1. carreteras y ferrocarriles. Madrid. Ed. Ministerio de Obras Públicas y Transportes.

NUTLEY, S. (2005): «Monitoring rural travel behaviour: a longitudinal study in Northern Ireland 1979-2001». Journal of Transport Geography, 13-3.

OWEN, D. et al. (2012): «Skills, transport and economic development: evidence from a rural area in England». Journal of Transport Geography, 21.

RETZLAFF, R. (2000): «Buses replace private cars on Zion Park Scenic Drive». Planning, 66-7. 
SHIFTAN, Y. et al. (2006): «Demand for park shuttle services - a stated-preference approach». Journal of Transport Geography, 14.

SODECAN (2005): Plan de desarrollo de La Gomera, Santa Cruz de Tenerife.

STRADLING, S. (2007): «Passenger perceptions and the ideal urban bus journey experience». Transport Policy, 14.

TRAGSATEC (2011): Plan de Uso Público. Parque Nacional de Garajonay. San Sebastián de La Gomera. Grupo TRAGSA (inédito).

TRANSPORT 2000 TRUST (2001): Tourism without traffic: a good practice guide. London. Ed. Transport 2000 Trust.

TURNBULL, K. F. (2003): «Transport to nature: transportation strategies enhancing visitor experiences of national parks». TR News, 224.

VELAGA, N. et al. (2012): «Transport poverty meets the digital divide: accessibility and connectivity in rural communities». Journal of Transport Geography, 21.

WHITE, D. (2007): «An interpretative study of Yosemite National Park visitors' perspectives toward alternative transportation in Yosemite Valley». Environmental Management, 39. 
